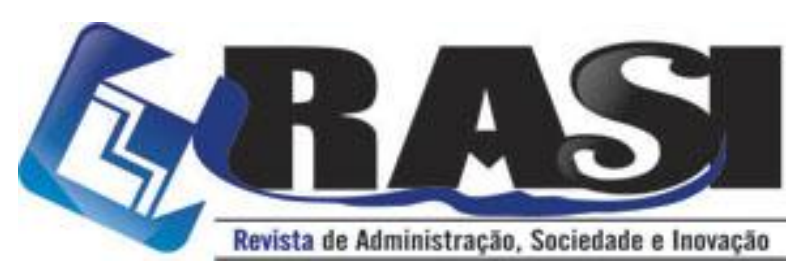

http://www.rasi.uff.br

RASI, Volta Redonda/RJ, v.4, n.2, pp.106-111, jul./dez. 2018

Rotular não é Preciso! Reflexões sobre a Dicotomia “Qualitativo-Quantitativo" em Administração/Gestão

Márcio Moutinho Abdalla (UFF) - marcioabdalla@id.uff.br

Vanessa da Silva Garcia (UFF) - vanessagarcia@id.uff.br

Ricardo César da Silva Guabiroba (UFF) - ricardocesar@id.uff.br

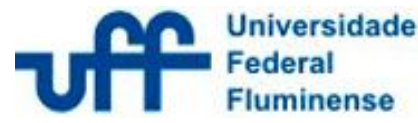

R. Desembargador Ellis Hermydio Figueira, 783, Bloco A, sl. 304, Aterrado.

27213-145 - Volta Redonda, RJ - Brasil

www.uff.br

Copyright ( 2018 RASI. Todos os direitos, até mesmo de tradução, são reservados. É permitido citar parte de artigos sem autorização prévia, desde que seja identificada a fonte. 


\section{Rotular não é Preciso! Reflexões sobre a Dicotomia “Qualitativo-Quantitativo" em Administração/Gestão}

O debate sobre a potencial complementariedade entre pesquisas de abordagem qualitativa e pesquisas de abordagem quantitativa apresenta longa trajetória temporal no campo de conhecimento da administração/gestão. É possível identificar esforços sobre essa discussão desde os anos de 1970, a exemplo de Downey \& Ireland (1979) e Kilmann \& Mitroff (1976), até trabalhos mais recentes, que tratam dos desdobramentos dessa temática, a partir de estudos sobre planejamento, elaboração, aplicação e desenvolvimento de métodos mistos de pesquisa (e.g. Abdalla, Oliveira, Azevedo, \& Gonzalez, 2018; Fielding, 2012; Gibson, 2017; Greene, 2008; Kern, 2018; Turner, Cardinal, \& Burton, 2017). Contudo, há menor escala em esforços empreendidos no que se refere à problematização da dicotomia historicamente instituída entre as abordagens qualitativa e quantitativa de pesquisa.

Compreendemos que a radical separação entre as abordagens de pesquisa seja problemática para os processos de construção de conhecimento. Podemos exemplificar parte desse problema a partir dos impactos produzidos na formação de estudantes de stricto sensu, quando são "convidados" a escolherem uma abordagem (ou trilha) de pesquisa, que possivelmente ditará suas escolhas ao longo de sua vida acadêmica. Também é possível exemplificar parte desses problemas por meio dos processos de estigmatização de acadêmicos, em pesquisadores "quali" OU pesquisadores "quanti". Uma vez rotulados, não é raro observar colegas auto-cerceados de pensarem e problematizarem a partir de paradigmas “outros", já que fulano É “quali” OU fulano É "quanti", como uma consequência direta da coprodução identitária, concebida de forma fictícia. Essa segregação epistêmica, que estabelece a tomada de posicionamentos monoparadigmáticos, seguida pela superestimação de únicas vias metodológicas, vem favorecendo a manutenção do status quo científico e seus consequentes desdobramentos (Sauerbronn, 2013), acarretando em um verdadeiro desfavor científico ao campo de administração/gestão.

A distinção entre abordagens também contribui para tornar a descrição metodológica mais rasa e mais superficial, especialmente em situações que os métodos de pesquisa são descritos simplesmente como "métodos qualitativos" ou "métodos quantitativos" (Allwood, 2012), como se essa mera declaração fosse suficiente para assegurar a compreensão da sistematização e do percurso metodológico, além de sua potencial replicabilidade. Pelas razões expostas, além de outras que pretendemos melhor discutir oportunamente, acreditamos que rotular não é preciso! Rotular não é preciso, nem no sentido de acuracidade, nem no sentido de necessidade. No primeiro caso, existem autores que defendem a existência de imprecisão, bem como inutilidade na dicotomização e consequente declaração das abordagens de pesquisa em trabalhos científicos (e.g. Allwood, 2012; Pope \& Mays, 1999). Essa imprecisão é motivada por diversas razões, que são relacionadas e devidamente discutidas por Allwood (2012) em um importante trabalho. Um dos pontos que chama a atenção é a própria imprecisão do conceito de "pesquisa qualitativa" e, por conseguinte, o que se classifica como "pesquisa quantitativa", levando a crer que essa dicotomia é rasa e pobre. O quadro 1, que reproduz o esforço do autor em discutir essa imprecisão fala por si só, ao apresentar 
distintas opiniões de autores seminais sobre propriedades e características que determinam o que viria a ser "pesquisa qualitativa".

Quadro 1. Diferentes opiniões sobre propriedades e características da abordagem qualitativa.

\begin{tabular}{|l|c|}
\hline \multicolumn{1}{|c|}{ Características e propriedades da abordagem qualitativa } & Autor (es) \\
\hline $\begin{array}{l}\text { Nenhuma estatística ou outras formas de quantificação são ou devem } \\
\text { ser usadas. }\end{array}$ & Strauss \& Corbin (1998) \\
\hline A abordagem qualitativa é emancipadora. & Hamilton (1998) \\
\hline $\begin{array}{l}\text { A abordagem qualitativa é interpretativa naturalista, ou seja, não está } \\
\text { baseada em laboratório. }\end{array}$ & Denzin \& Lincoln (1998) \\
\hline Palavras são dados. & Tesch (1990) \\
\hline Conteúdos dos significados são o objeto de estudo. & Pope \& Mays (1999) \\
\hline $\begin{array}{l}\text { A abordagem qualitativa é radicalmente interpretativa e construtivista, } \\
\text { isto é, pressupõe que não há realidade independente da investigação. }\end{array}$ & Sale, Lohfeld \& Brazil (2002) \\
\hline
\end{tabular}

Fonte.: Allwood (2012).

Também compreendemos que "rotular não é preciso" no que tange à inflexível e mandatória "necessidade" de declarar qual abordagem é engajada em cada trabalho. Não se trata do abandono da descrição e da sistematização metodológica. Ao contrário! Criticamos justamente o descrever, por descrever, sem refletir o que de fato está sendo abordado. Não é raro nos depararmos com pesquisas que empregam técnicas metodológicas situadas no limiar das abordagens, a exemplo de alguns tipos de Análise de Conteúdo. É comum encontrar situações em que autores são impelidos a declarar, de forma irrefletida que, por se caracterizar por uma análise textual, trata-se tipicamente de abordagem qualitativa, ainda que a técnica empregue estatísticas como mecanismos analíticos. Dessa forma, concordamos com Allwood (2012), quando defende que essa separação é imprecisa, sendo mais proveitoso e contributivo, concentrar esforços sobre o contexto e os problemas de pesquisa específicos de cada trabalho. A partir de cada problematização, é possível identificar um conjunto de métodos mais apropriados para o alcance dos propósitos da pesquisa, e não o contrário, a partir do estigma do pesquisador "quali" OU do pesquisador "quanti", escolhermos os problemas que melhor se adaptem ao ferramental metodológico disponível.

A partir das incipientes provocações manifestas nesse volume, saudamos leitores, autores, revisores e toda comunidade acadêmica, apresentando os trabalhos dessa edição. No primeiro trabalho, sob o título "A Baixa Internacionalização das Empresas Brasileiras: Uma Análise das Principais Barreiras Institucionais", de Danilo Castanha Mariotti, Felipe Mendes Borini, Leandro Lima dos Santos e Rafael Morais Pereira, analisam-se as características do ambiente institucional brasileiro, que impõe barreiras ao processo de internacionalização de empresas nacionais. Os obstáculos referentes à tributação mostram-se mais acentuados em relação às empresas não internacionalizadas, enquanto as barreiras referentes à infraestrutura nacional afetam tanto empresas internacionalizadas quanto não internacionalizadas.

O segundo trabalho, sob o título "Gestão de Redes de Empresas e Technology Roadmapping: possibilidades para uma abordagem estratégica" de autoria de Luiz Guilherme Rodrigues Antunes, Thais Assis de Souza e Cléber Carvalho de Castro 
consiste de um ensaio teórico. Os autores buscam evidenciar a relação entre redes empresariais e o ferramental de apoio ao planejamento estratégico denominado technology roadmapping (ou TRM). Como principal achado, os autores defendem que o TRM pode suportar a gestão de redes interorganizacionais, apoiando processos estratégicos, a exemplo da criação de portfólios, da transferência tecnológica, de conhecimento e de integração de competências.

"Estratégia como prática para o enfrentamento da crise hídrica: Um olhar para os praticantes" é o título do terceiro trabalho, de autoria de Ivan Fernandes da Cruz, João Eduardo Ribeiro, Luana Jéssica Oliveira Carmo e Lilian Bambirra de Assis. À luz da estratégia como prática, os autores se propuseram a analisar as estratégias implementadas por praticantes na Usina Hidrelétrica de Energia (UHE) Três Marias, situada em Minas Gerais, ao longo do período de agravamento da crise hídrica nacional. Além da articulação entre as ações identificadas na implementação e os elementos teóricos, pode-se verificar que a tomada de decisão coletiva (práxis) promoveu atraso nas ações estratégicas em função do conflito de interesses de praticantes.

No quarto trabalho, de autoria de Fernanda Aparecida Guedes Honorato da Silva, Mirelle Cristina de Abreu Quintela e Naldeir dos Santos Vieira, desenvolve-se uma investigação empírica. Sob o título "Perfil Orçamentário de Pequenos Municípios: O Caso do Município de Ladainha - MG", os autores analisam dados dos períodos de 2000 a 2016, buscando identificar a captação e a origem das receitas, além da natureza e da finalidade das despesas, no intuito de identificarem o perfil orçamentário do município de Ladainha-MG. Como principal achado, verificou-se que, em função de seu perfil predominantemente rural e de seu pequeno porte, a arrecadação própria do município mostra-se insuficiente para arcar com seus gastos, concentrados majoritariamente nas áreas de Educação e Cultura e Saúde e Saneamento. Dessa forma, o município depende das transferências intergovernamentais para honrar seus gastos.

Sob o título "Determinantes da Estrutura de Capital no Brasil: Evidências Empíricas a partir de Dados em Painel no período entre 2010 e 2016", o quinto trabalho é de autoria de Mario Cordeiro Filho, João Batista Pamplona, Edimilson Costa Lucas e Ricardo Makoto Kawai. Os autores analisam os fatores determinantes da estrutura de capital de companhias abertas brasileiras listadas na BM\&BOVESPA entre os anos de 2010 e 2016, à luz da pecking order theory e da tradeoff theory. Como principal achado, os autores identificam que as companhias abertas brasileira são substancialmente financiadas por meio da emissão de dívida, fortalecendo os pressupostos do modelo da pecking order theory, ao passo que não são encontradas evidências convincentes que se relacionam ao modelo da tradeoff theory.

O trabalho "O Uso da Accountability Theory em Pesquisas sobre Transparência Governamental: Abordagens e Perspectivas", sob autoria de Rodrigo Hickmann Klein, Deisy Cristina Barbiero Klein e Edimara Mezzomo Luciano fecha essa edição. A partir de uma revisão sistematizada da literatura, os autores identificaram abordagens e estratégias de pesquisa sobre a chamada Accountability Theory (AT). Os autores defendem que o campo de pesquisas em AT é bastante fértil, englobando aspectos de transparência e combate à corrupção. Defendem ainda a legitimidade desse campo de estudos com base nos processos de prestação de contas e consequente responsabilização de agentes em situações tidas como não conformes. 
Em conformidade com nossos propósitos editoriais (ver Abdalla, 2018), seguimos participante de mais dois fast tracks de eventos no segundo semestre de 2018, sendo o XXI SemeAd, na USP, o primeiro deles; e o XI CASI, que nesse ano será realizado na ECEME (Escola de Comando e Estado-Maior do Exército), no Rio de janeiro-RJ. Agradecemos a todas as pessoas que contribuíram com a construção dessa edição, desejando uma ótima leitura!

\section{Referências}

Abdalla, M. M. (2018). Crescendo Sustentavelmente numa Linha Editorial Transparente. Revista de Administração, Sociedade e Inovação, 4(1), 1. https://doi.org/10.20401/rasi.4.1.228

Abdalla, M. M., Oliveira, L. G. L., Azevedo, C. E. F., \& Gonzalez, R. K. (2018). Quality in Qualitative Organizational Research: types of triangulation as a methodological alternative. Administração: Ensino e Pesquisa, 19(1), 66-98. https://doi.org/10.13058/raep.2018.v19n1.578

Allwood, C. M. (2012). The distinction between qualitative and quantitative research methods is problematic. Quality \& Quantity, 46(5), 1417-1429. https://doi.org/10.1007/s11135-011-9455-8

Downey, H. K., \& Ireland, R. D. (1979). Quantitative Versus Qualitative: Environmental Assessment in Organizational Studies. Administrative Science Quarterly, 24(4), 630. https://doi.org/10.2307/2392368

Fielding, N. G. (2012). Triangulation and Mixed Methods Designs. Journal of Mixed Methods Research, 6(2), 124-136. https://doi.org/10.1177/1558689812437101

Gibson, C. B. (2017). Elaboration, Generalization, Triangulation, and Interpretation. Organizational Research Methods, 20(2), 193-223. https://doi.org/10.1177/1094428116639133

Greene, J. C. (2008). Is Mixed Methods Social Inquiry a Distinctive Methodology? Journal of Mixed Methods Research, 2(1), 7-22. https://doi.org/10.1177/1558689807309969

Kern, F. G. (2018). The Trials and Tribulations of Applied Triangulation: Weighing Different Data Sources. Journal of Mixed Methods Research, 12(2), 166-181. https://doi.org/10.1177/1558689816651032

Kilmann, R. H., \& Mitroff, I. I. (1976). Qualitative versus Quantitative Analysis for Management Science: Different Forms for Different Psychological Types. Interfaces, 6(2), 17-27. https://doi.org/10.1287/inte.6.2.17

Pope, C., \& Mays, N. (1999). Qualitative methods in health research. In C. Pope \& N. Mays (Eds.), Qualitative research in health care (pp. 1-10). London: BMJ Books.

Sauerbronn, J. F. R. (2013). Diga-me o que publicas e te direi quem és: Perspectivas e 
resistências na publicação da produção de conhecimento em Marketing. Revista de Negócios, 18(1). https://doi.org/10.7867/1980-4431.2013v18n1p42-52

Turner, S. F., Cardinal, L. B., \& Burton, R. M. (2017). Research Design for Mixed Methods. Organizational Research Methods, 20(2), 243-267. https://doi.org/10.1177/1094428115610808 